\title{
Raised serum levels of IGFBP-1 and IGFBP-2 in idiopathic pulmonary fibrosis
}

\author{
J. Guiot ${ }^{1 *}$, B. Bondue ${ }^{2}$, M. Henket ${ }^{1}$, J. L. Corhay ${ }^{1}$ and R. Louis ${ }^{1}$
}

\begin{abstract} them with healthy subjects. still significantly elevated in comparison to HS $(p<0.001)$. anti-fibrosing therapy. IGFBPs may be promising biomarkers in IPF. binding proteins

\section{Background}

Idiopathic pulmonary fibrosis (IPF) is a complex diagnosis and pathology requiring a multidisciplinary approach. This fibrotic disease has a poor prognosis and requires a specific and early appropriate therapy [1-3]. In this context several biomarkers (such as surfactant protein A or SP-A, the Krebs von den Lungen 6 or KL-6, Ig A and periostin [4-8] were studied without much success to be discriminant as early diagnostic biomarkers to identify IPF out of different interstitial lung diseases (ILDs). Nevertheless when taken together they provided convincing evidence that changes in blood proteins (KL-6, SP-A, MMP-7, CCL-18, among others) or cells (fibrocytes and T-cell subpopulations) are indicative in IPF and may somewhat predict outcome of the disease [9].
\end{abstract}

Background: Idiopathic pulmonary fibrosis (IPF) is a chronic lung disorder of unknown origin, which ultimately leads to death. Several growth factors such as IGFs (insulin-like-growth factor) and IGFBPs (insulin like growth factor binding proteins) seem to take part to the pathogenesis. We evaluated IGFs and IGFBPs in serum from patients with IPF and healthy subjects including 24 untreated IPF and 26 IPF receiving anti-fibrotic therapy and to compare

Methods: Serum of 50 idiopathic pulmonary fibrosis and 55 healthy subjects (HS) were analysed by ELISA for IGFs and IGFBPs, TGF- $\beta$ and KL-6, the latter being tested as positive control in IPF.

Results: Serum levels of IGFBP-1 and IGFBP-2 and KL- 6 were significantly higher in the IPF group than in the healthy subjects ( $p<0.05, p<0.001$ and $p<0.0001$ respectively) while the picture was inversed regarding IGFs. By contrast there was no significant difference between the groups with respect to TGF- $\beta$. IGFBP-2 was significantly reduced in the patients with specific anti-fibrotic therapy pirfenidone and nintedanib compared to untreated patients $(p<0.05)$ but

Conclusion: Serum IGFBP-1 and -2 are increased in idiopathic pulmonary fibrosis and IGFBP-2 may be reduced by

Keywords: Idiopathic pulmonary fibrosis, Pulmonary fibrosis, Insuline-like growth factors, Insulin like growth factor

\footnotetext{
* Correspondence: J.Guiot@chu.ulg.ac.be

${ }^{1}$ Pneumology Department, CHU Liège, Domaine universitaire du Sart-Tilman, B35, B4000 Liège, Belgium

Full list of author information is available at the end of the article
}

The transforming growth factor beta (TGF- $\beta$ ) has long been known to be involved in the pathophysiology of the IPF [1]. TGF- $\beta$ is a stimulus for pulmonary fibrogenesis by its activity in the control of the remodelling of the extracellular matrix. TGF- $\beta$ is also known to be involved in the fibroblast activity.

Besides TGF- $\beta$, there has been recently a growing interest for the axis IGFs/IGFBPs in fibrosing process. A recently published study has shown a link between the production of TGF- $\beta$ and the production of insulin-like growth factor binding protein-2 (IGFBP-2) [10] known to be related to IPF [11] within myofibroblasts cells derived from the lung. Moreover, IGFBP-2 was found at significantly higher level in the bronchoalveolar lavage of children with interstitial lung disease [12] relative to healthy subjects.

IGFBP-2 is also overexpressed in response to a deterioration of the lung parenchyma [13-15]. This overexpression is mainly perinuclear and proves to be a potential factor of 
fibroblast proliferation [16-19]. The IGFBP-2 protein is part of a group (IGFBPs) known to be involved in the regulation of insulin-like growth factor (IGF). IGF-1 and IGF-2 play an important role in the growth, differentiation and cellular metabolism [20, 21]. Signalling pathway of IGF consisted of two isoforms of IGF ( -1 and -2$)$, two types of receptors, six binding proteins with high affinity for IGFs (IGFBPs) and four binding proteins with low affinity for IGFs (or related protein IGFBP: IGFBPrp) [11, 22, 23]. The IGFBPs bind IGFs and can increase their half-life, alter their function (in potentiating or inhibiting it), or facilitate their passage to the target tissues [20, 24]. Activity of IGFBP-2 is controlled on one hand by its secretion and on the other hand by its proteolysis. Proteolysis of IGFBP-2 is made by several groups of proteolytic enzymes such as pappalysines, kallikreins, metalloproteases or the plasmin [25].

There has been recent pharmacological progress in the treatment of IPF. Drugs such as pirfenidone and nintedanib have been shown to slow down the decline in lung volume that accompanies the lung fibrosing process [2].

We focused our study on the serum measurement of several growth factors including IGFs and IGFBPs in order to identify a potential new biomarker in IPF and sought to determine whether their levels might be influenced by recently developed anti-fibrotic therapy.

\section{Methods}

\section{Subject characteristics}

We prospectively recruited patients from our ambulatory care policlinic at $\mathrm{CHU}$ Liege and Erasme University Hospital of Brussels. The patients were divided into 2 groups. The first group was the group of patients with untreated IPF $(n=24)$. The second group is a group of treated IPF patients with a specific therapy $(n=26)$. The diagnosis of (definite) IPF was made according to the international recommendations of the ATS [1] using the respiratory function test, HRCT scan (probable UIP pattern), bronchoalveolar lavage (when available), as well as the clinical history of the patient. We excluded all other causes of interstitial lung disease (such as asbestosis, hypersensitivity pneumonitis, pneumonia associated with connective tissue disease or toxic pneumonitis). We combined the different results for the diagnosis. All cases were discussed in a multidisciplinary group about interstitial lung diseases composed of a pulmonologist, a specialist in pulmonary rehabilitation, a rheumatologist, a radiologist, a pathologist and a specialist in occupational medicine. Sixteen patients underwent a surgical biopsy and seven patients transbronchial cryobiopsies. Twenty-six patients benefit from a specific treatment of IPF (pirfenidone $(n=17)$ or nintedanib $(n=9)$ ) Fig. 1 . We also recruited healthy subjects by advertisement in our policlinic waiting room. They all denied any respiratory disease and had normal spirometric values with FEV1 $>80 \%$ predicted and FEV1/FVC ratio $>70 \%$.

The protocol was approved by the ethics committee of CHU of Liège, and all subjects gave written consent before their enrollment (Belgian number : B707201422832; ref : 2014/302).

\section{Peripheral blood puncture}

Venous blood was collected in Vacutainer tubes from an antecubital site immediately when controls and patients were included in the study. Blood cell values included white blood cell count, the differential leukocyte count, fibrinogen and C-reactive protein (CRP) levels were determined by the routine hospital laboratory.

\section{Biomarkers measurements in serum}

We analysed several biomarkers assumed to be critical growth factors in blood: TGF- $\beta$, IGF-1, IGF-2, IGFBP-1, IGFBP-2 and IGFBP-3 were measured by a specific enzyme immunoassay with a commercial kit (TGF- $\beta$, IGF1, IGFBP-1, IGFBP-2, IGFBP-3: Duoset ${ }^{\bullet}$, R\&D systems, Minneapolis; IGF-2 : Mediagnost, Reutlingen, Germany; KL-6 level was measured by a specific enzyme immunoassay with a commercial kit (Lumipulse G KL-6 Fujirebio Europe).

\section{Pulmonary function tests}

We performed lung function tests in both routine respiratory laboratory of CHU Liège and Erasme University hospital. All spirometric tests performed for this study were measured using the pneumotachograph JaegerMasterlab system (Erich Jaeger GmbH, Wuzburg, Germany). The forced expiratory volume in one second (FEV1) and forced vital capacity (FVC) were measured in accordance with the recommendations of the European Respiratory Society (ERS) [26]. The results were expressed in millilitre and percent predicted. The Tiffeneau index or FEV1/FVC was expressed in percent. The total lung capacity (TLC) was measured by body plethysmography according to ERS recommendations (Erich Jaeger $\mathrm{GmbH}$, Wuzburg, Germany). The diffusion capacity of CO (DLCO) and the report DLCO/AV were measured by the single-breath carbon monoxide gas transfer method and expressed as percent predicted (Sensor Medics $2400 \mathrm{He} / \mathrm{CO}$ Analyzer System, Bilthoven, Netherlands).

\section{Statistical analysis}

Demographic and functional data were expressed as mean \pm standard deviation (SD). The biomarkers levels were expressed as median (min-max). When the data showed normal distribution, they were compared with a one-way ANOVA, followed by Tukey-Kramer's post-hoc testing. When the data did not show a normal distribution, they were compared with the Kruskal-Wallis test 


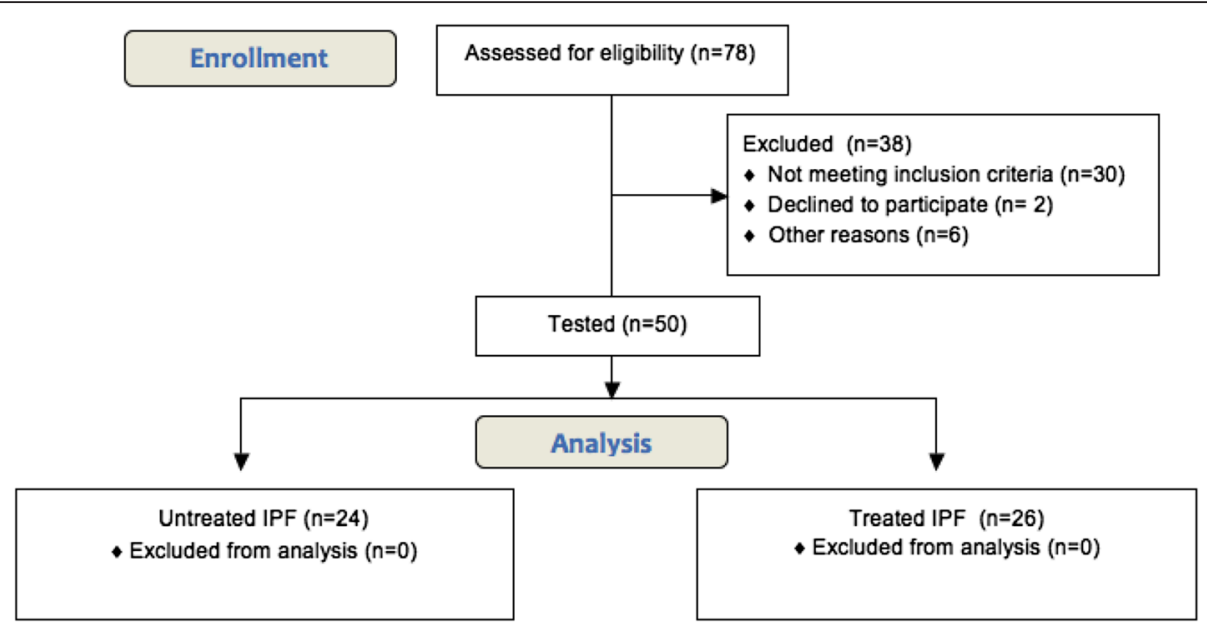

Fig. 1 CONSORT flow chart

followed by Dunn's post-hoc testing. Correlations between variables were performed using Spearman's rank correlation test. A $p<0.05$ was considered as significant.

\section{Results}

Subject demographic functional and blood characteristics The demographic, functional and treatment characteristics of the subjects are given in Table 1 . The average age of IPF patients was slightly higher $(74 \pm 9$ years for untreated patients versus $68 \pm 9$ years for treated patients) with a male dominance. Spirometric values were moderately lowered and comparable in both the treated and untreated IPF while DLCO was sharply reduced in both IPF groups.

There was a significant increase in leukocyte count of untreated and treated IPF patients $(p<0.0001)$. IPF patients also displayed neutrophil (treated IPF : $p<0.0001$; untreated IPF : $p<0.001$ ), monocyte (treated IPF $: p<0.0001$; untreated IPF $: p<0.0001$ ) and eosinophil counts (treated IPF : $p>0.05$; untreated IPF $: p<0.001$ ) compared to HS (Table 1). By contrast, circulating lymphocyte count was reduced in untreated IPF compared to HS. There was an increase in fibrinogen and CRP levels in untreated IPF compare to HS (Table 1).

\section{Serum growth factors}

The results of the serum biochemical markers are listed in the Table 2. There was a striking increase in IGFBP-1 and -2 in the group of untreated IPF patients compared to healthy subjects (respectively $p<0.05, p<0.0001$ ) (Figs. 2-3), while untreated IPF showed a significant decrease in serum IGF-1 $(p<0.05)$ IGF-2 $(p<0.01)$ and IGFBP-3 $(p<0.01)$. IGFBP-2 levels were lower in those patients receiving anti-fibrotic therapy but still significantly elevated compared to HS $(p<0.001)$ (Fig. 3).
IGFBP-2 seems to be significantly lowered by specific IPF therapy irrespective of the molecule used as antifibrotic treatment (median range of 189 (110-231) $\mathrm{ng} / \mathrm{ml}$ in the group treated by nintedanib $(n=9)$ vs $155(126-192) \mathrm{ng} / \mathrm{ml}$ in those receiving pirfenidone $(n=17), p>0.05)$.

Similarly to IGFBP-2, KL-6 was increased in both IPF groups compared to HS $(p<0.0001)$ (Fig. 3). By contrast there was no significant difference between the groups regarding the levels of TGF- $\beta$.

We also calculated the serum molar ratio of IGFs:IGFBPs known as reflecting the real IGFs activity (Table 2). Serum ratios of IGF-1:IGFBP-1 $(p<0.01)$, IGF-1:IGFBP-2 $(p<0.0001)$, IGF-2:IGFBP-1 $(p<0.05)$ and IGF-2:IGFBP-2 $(p<0.0001)$ were significantly lower in the not treated IPF group than in healthy subjects (Table 2).

\section{Relationship between growth factors and lung function}

There was an inverse relationship between spirometric values and TGF- $\beta$ in healthy subjects (FVC \% pred $R=-0.50, p<0.05$ and FEV1 \% pred $R=-0.48, p<0.05$ ) and untreated IPF (FEV1 \% pred $R=-0.54, p<0.05$ ) and an inverse relationship between IGFBP-1 and DLCO in treated IPF $(R=-0.52, p<0.05)$. We didn't find any correlation between pulmonary function tests and IGFBP- 2 and other biomarkers assessed in our study (Additional file 1: Table S1).

\section{Discussion}

Our study shows for the first time that IPF features a marked increase in serum IGFBP-1 and IGFBP-2. In addition IGFBP-2 levels are attenuated in those patients receiving anti-fibrotic treatment even if the serum levels remained higher in than those measured in healthy subjects. 
Table 1 Patients demographic, functional, treatment and blood characteristics

\begin{tabular}{|c|c|c|c|}
\hline & Healthy subjects $n=55$ & Untreated IPF $n=24$ & Treated IPF $n=26$ \\
\hline Age, yrs & $60(8)$ & $74(9)^{* * *}$ & $68(9)^{* * *}$ \\
\hline Gender (M/F) & $28 / 27$ & $19 / 5$ & $16 / 3$ \\
\hline Height, cm & $170(8)$ & $168(10)$ & $170(9)$ \\
\hline Weight, Kg & $75(12)$ & $74(16)$ & $78(11)$ \\
\hline $\mathrm{BMl}, \mathrm{Kg} / \mathrm{m}^{2}$ & $26(3)$ & $26(4)$ & $27(3)$ \\
\hline Smokers (NS/FS/S) & $23 / 22 / 6$ & $3 / 8 / 6$ & $(6 / 19 / 0)$ \\
\hline Leucocytes $\times 10^{3} / \mu \mathrm{l}$ & $7.00(5.39)$ & $8.35(2.35)^{*}$ & $8.42(2.91)^{* *}$ \\
\hline 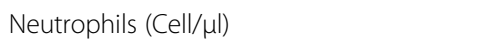 & $3450(1025)$ & $5614(2113)^{* * *}$ & $5960(3053)^{* * *}$ \\
\hline Lymphocytes (Cell/ul) & $2085(620)$ & $1676(825)^{*}$ & $1786(643)$ \\
\hline 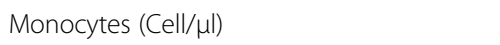 & $486(160)$ & $698(325)^{* *}$ & $725(218)^{* * *}$ \\
\hline 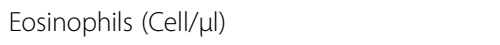 & $173(125)$ & $314(266)^{* *}$ & $214(128)$ \\
\hline Basophils (Cell/ $\mu l)$ & $33(17)$ & $55(67)$ & $94(187)$ \\
\hline Fibrinogen (g/l) & $3(0.80)$ & ${ }^{a} 4(1.40)^{* * *}$ & nd \\
\hline CRP (mg/l) & $1.9(2.89)$ & $\mathrm{a}_{30}(37.89)^{* * *}$ & nd \\
\hline FEV1 post-BD, \%pred. & $105(12)$ & $75(14)^{* * *}$ & $67(13)^{* * *}$ \\
\hline FVC post-BD, \%pred. & $111(16)$ & $73(14)^{* * *}$ & $66(16)^{* * *}$ \\
\hline TLC, \%pred. & nd & $71(19)$ & $68(15)$ \\
\hline DLCO \%pred. & nd & $37(11)$ & $38(13)$ \\
\hline KCO \%pred. & nd & $63(16)$ & $70(20)$ \\
\hline Treatment (pirfenidone/nintedanib) & $0 / 0$ & 0/0 & $17 / 9$ \\
\hline Pirfenidone (duration of treatment -Month) & nd & nd & $9.9(7.4)$ \\
\hline Nintedanib (duration of treatment -Month) & nd & nd & $14.3(15.8)$ \\
\hline
\end{tabular}

nd not determined

Data are expressed as mean (SD)

Non smoker (NS), former smoker (FS), smoker (S)

${ }^{*} p<0.05{ }^{* *} p<0.001{ }^{* * *} p<0.0001$ compared to healthy subjects

$a_{n}=13$

Table 2 Serum biomarkers

\begin{tabular}{llll}
\hline & Healthy subjects & Untreated IPF & Treated IPF \\
\hline IGF-1 $(\mathrm{ng} / \mathrm{ml})$ & $31(7-67)$ & $20(9-102)^{*}$ & $25(11-57)$ \\
IGF-2 $(\mathrm{ng} / \mathrm{ml})$ & $710(401-2232)$ & $590(210-1027)^{*}$ & $586(282-920)^{* *}$ \\
IGFBP-1 $(\mathrm{ng} / \mathrm{ml})$ & $11(0-180)$ & $22(4-110)^{*}$ & $9(1-107)$ \\
IGFBP-2 $(\mathrm{ng} / \mathrm{ml})$ & $94(34-211)$ & $206(113-317)^{* *}$ & $153(32-291)^{* *}$ \\
IGFBP-3 $(\mathrm{ng} / \mathrm{ml})$ & $2132(1207-4059)$ & $1536(534-2556)^{*}$ & $2032(893-3505)$ \\
Molar ratio IGF-1 : IGFBP-1 & $12(1-314)$ & $3,5(0,3-36,3)^{*}$ & $9(1-152)$ \\
Molar ratio IGF-1 : IGFBP-2 & $1,8(0,2-6,2)$ & $0,4(0-4,3)^{* * *}$ & $0,7(0,3-5,2)^{*}$ \\
Molar ratio IGF-1 : IGFBP-3 & $0,06(0,02-0,12)$ & $0,05(0,03-0,25)$ & $0,05(0,03-0,1)$ \\
Molar ratio IGF-2 : IGFBP-1 & $247(20-6735)$ & $110(11-769)^{*}$ & $259(20-2429)$ \\
Molar ratio IGF-2 : IGFBP-2 & $40(10-202)$ & $14(5-28)^{* * *}$ & $19(7-89)^{* *}$ \\
Molar ratio IGF-2 : IGFBP-3 & $1,4(0,8-5,1)$ & $1,6(0,6-2,2)$ & $1,2(0,9-1,8)$ \\
TGF- $\beta$ (ng/ml) & $11(3-21)$ & $11(5-22)$ & $9(4-17)$ \\
KL-6 $(\mathrm{ng} / \mathrm{ml})$ & $262(83-596)$ & $1050(314-4951)^{* * *}$ & $889(359-6168)^{* * *}$ \\
\hline
\end{tabular}

Data are expressed as median (min-max) 


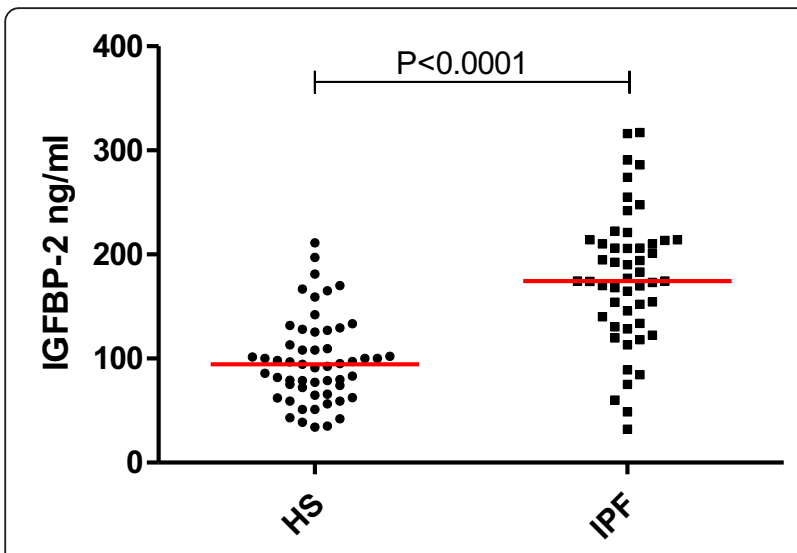

Fig. 2 Serum IGFBP-2 concentration: Comparison between IPF and healthy subjects. $H S=$ healthy subjects $(n=55)$; IPF = idiopathic pulmonary fibrosis ( $n=50$ : treated and untreated)

Previous studies focusing on IGFBP-2 in fibrosis showed an increase of IGFBP-2 in the bronchoalveolar lavage [12] and in the lung tissue of patients with interstitial lung disease (ILD) without focusing on IPF. IGFBP-2 was shown to be overexpressed in case of lung epithelial damage $[12-15,27]$ and its expression was found to be reduced, together with that of TGF- $\beta$, by cyclosporine in vitro [10]. The assay of IGFBP-2 in the serum of patients with idiopathic pulmonary fibrosis had never been done before. In our current study IGFBP-2 was significantly higher in the serum of patients with IPF compared to healthy subjects. Of great interest, serum IGFBP-2 decreases with specific anti-fibrotic treatments without returning to normal values however. It supports the idea that IGFBP-2 may play a role in the fibrotic process. As our patients were not treated with corticoids we can here discard any possible impact of corticosteroids on IGFBP levels [28].

Reinforcing the potential role of IGFBPs in IPF, IGFBP-1 was also specifically increased, but to a lesser extent, in IPF compared to HS. The increase of KL-6 in IPF versus healthy subjects is confirmatory of previous findings $[29,30]$ and validates our IPF patient cohort. In sharp contrast to what we found with IGFBP, serum IGF-1 and -2 were not found to be decreased in IPF in comparison to HS which results in a decrease ratio IGF:IGFBP in patients with IPF. IGFs are very potent growth factors [20] but, to the best of our knowledge, had not been studied in human lung fibrosis so far. In an animal model IGF-1 was shown to stimulate differentiation of fibroblast into myofibrolast [31], one of the effector of pulmonary fibrosis [32]. Intuitively we might have expected a direct relationship between IGFs and disease severity. However our study didn't show any correlation between IGF-:IGFBP ratio and functional impairment including forced vital capacity and total lung diffusing capacity. The rise of serum IGFBPs might be seen as a spill over of the

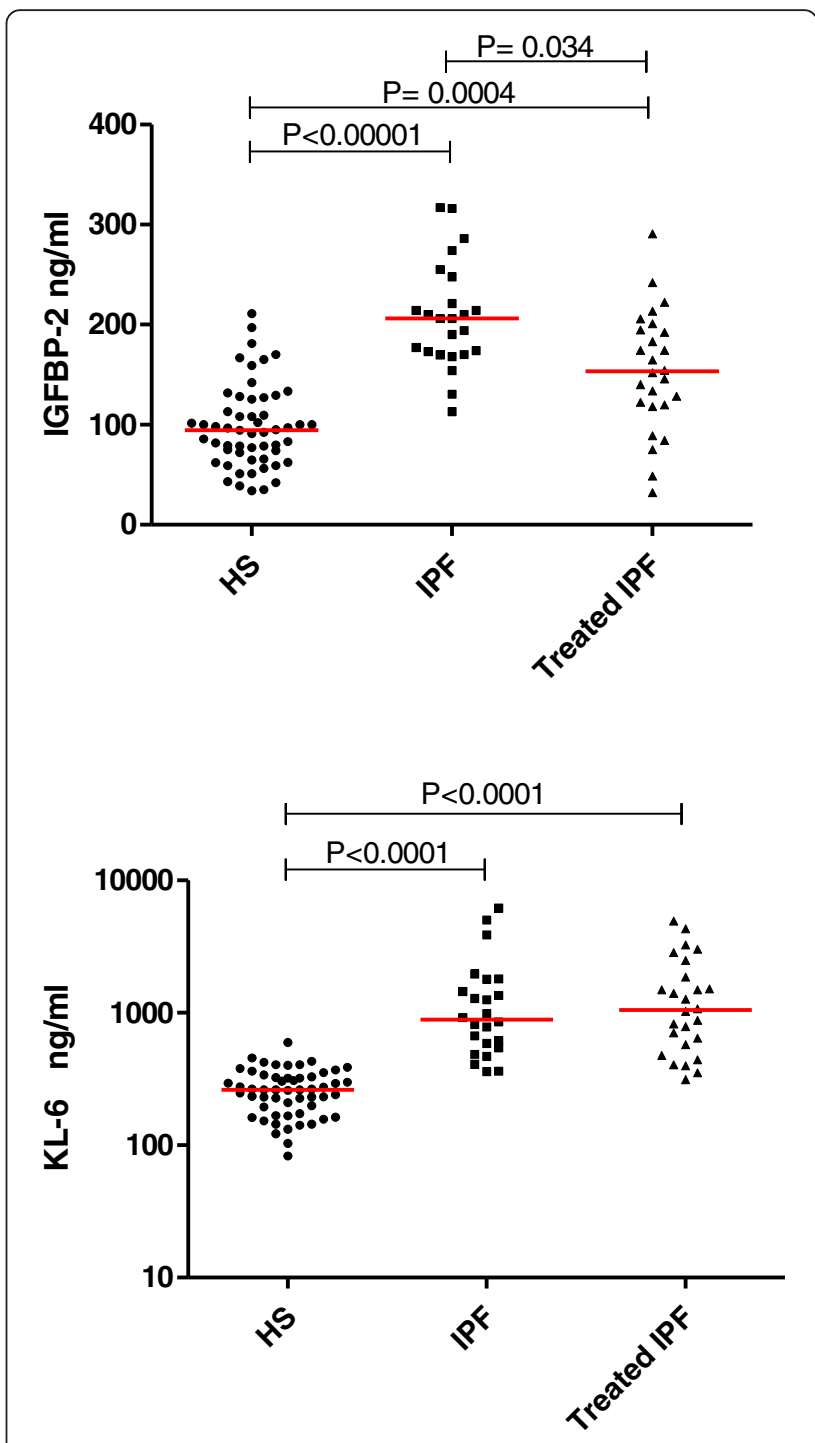

Fig. 3 Serum IGFBP-2 and KL-6 concentrations: Comparison between treated IPF, untreated IPF and healthy subjects. HS = healthy subjects; IPF = idiopathic pulmonary fibrosis

lung fibrotic process since previous studies showed raised levels in BAL from patients with ILD [12]. How IGFBP may favour lung fibrosis remains unclear. One potential explanation is IGFBP-2 can bind to the lung extracellular matrix [33] and thus can favour the IGF activity by increasing its local availability, which results in an increase of cellular response to IGF [34]. This trapping mechanism would explain why IGFs themselves were found to be reduced in serum from our patients. Alternatively we cannot rule out the fact that high IGFBP-2 in IPF may actually reflect a protective feed-back mechanism to limit the disease progression by neutralizing IGFs [35]. On the same line there is an example where IGFPB-2 is playing a protective role against anarchic cell proliferation. In non-small cell lung carcinoma, in vitro studies indicate that both soluble 
and membrane-associated IGFBP-2 competes with IGF receptors for ligand binding and, thus, are likely to be important determinants of IGF responsiveness [36]. Interestingly IGF-I and IGFBP-3 are lowered in untreated IPF patients in comparison to healthy subjects. This decrease is similar to what it has been shown in ARDS, cystic fibrosis and COPD [37]. Moreover these authors suggest that there may be an inverse association between circulating levels of IGF-1 and IGFBP-3 and lung compartments levels where they are upregulated suggesting a different lung and blood regulation under these circumstances.

In our study serum levels of TGF- $\beta$ were similar between the groups confirming the results described by a previous study [38]. Of course it does not mean that these molecules did not play a major role within the lung. Indeed TGF- $\beta$ is known to take part to the lung fibrosing process and was shown to be overexpressed in lung tissue of patients with IPF [39].

\section{Conclusion}

We conclude that serum IGFBP-1 and IGFBP-2 are increased in patients with idiopathic pulmonary fibrosis in comparison to healthy subjects. Moreover, the raised IGFBP-2 level is attenuated by anti-fibrotic treatment. The prognostic value of these new biomarkers warrants further longitudinal studies.

\section{Additional file}

Additional file 1: Table S1. Correlations between blood biomarkers and pulmonary function test. (DOCX $173 \mathrm{~kb}$ )

\section{Abbreviations}

ATS: American thoracic society; AV: Alveolar ventilation; CCL-18: chemokine (C-C motif) ligand 18; COPD: chronic obstructive pulmonary disease; DLCO: diffusion capacity of CO in the lung; FEV1: forced expiratory volume in one second; FVC: forced vital capacity; HRCT: high resolution computed tomography; IGF: insulin-like growth factor; IGFBP: insulin-like growth factor binding protein; IGFBP-rp: insulin-like growth factor binding protein related protein; ILD: interstitial lung disease; IPF: idiopathic pulmonary fibrosis; KL-6: Krebs von den Lungen-6; MMP: matrix metalloproteinase; NSIP: non specific idiopathic pulmonary fibrosis; SD: standard deviation; SP-A: surfactant protein-A; SPD: surfactant protein-D; TGF- $\beta$ : transforming growth factor beta; TLC: total lung capacity; YKL-40: Chitinase-3-like-1, human cartilage glycoprotein-39.

\section{Acknowledgment}

We thank Georgitha Amand for the collection of datas.

We thank the Leon Frederica ULG foundation for their financial support.

\section{Availability of data and materials}

The data supporting our results are presented within the article (and its Additional file 1: Table S1).

\section{Authors' contribution}

$\mathrm{RL}$ and $J \mathrm{LC}$ for their involvement in conception, hypothesis, and design of the study. MH for the acquisition and analysis of samples. BB for his help in the recruitment. All authors read and approved the final manuscript.

\section{Competing interests}

The authors declare that they have no competing interests.
Consent for publication

Not applicable.

\section{Ethics approval and consent to participate}

The protocol was approved by the ethics committee "hospitalofacultaire" of Liège, and all subjects gave written consent before their enrolment (Belgian number : B707201422832; ref : 2014/302).

\section{Author details}

'Pneumology Department, CHU Liège, Domaine universitaire du Sart-Tilman, B35, B4000 Liège, Belgium. Pneumology Department, Erasme University Hospital, Université Libre de Bruxelles, Route de Lennik, 808, B1070 Brussels, Belgium.

Received: 26 January 2016 Accepted: 16 May 2016

Published online: 23 May 2016

\section{References}

1. Ganesh Raghu HRC, Egan JJ, Martinez FJ, Juergen B, Brown KK, Colby TV, Jean-François C, Flaherty KR, Lasky JA, Lynch DA, Ryu JH, Swigris JJ, Wells AU, Julio A, Demosthenes B, Carlos C, Ulrich C, Masahito E, Hansell DM, Takeshi J, Dong Soon K, King TE Jr, Yasuhiro K, Jeffrey M, Müller NL, Nicholson AG, Luca R, Moisés S, Dudden RF, Griss BS, Protzko SL, Schünemann HJ. An Official ATS/ERS/JRS/ALAT Statement: Idiopathic Pulmonary Fibrosis: Evidence-based Guidelines for Diagnosis and Management. Am J Respir Crit Care Med. 2011;183(6):788-824.

2. Wilson KC, Raghu G. The 2015 guidelines for idiopathic pulmonary fibrosis: an important chapter in the evolution of the management of patients with IPF. Eur Respir J. 2015;46(4):883-6.

3. Spagnolo P, Tonelli R, Cocconcelli E, Stefani A, Richeldi L. Idiopathic pulmonary fibrosis: diagnostic pitfalls and therapeutic challenges. Multidiscip Respir Med. 2012;7(1):42.

4. Ohshimo S, Ishikawa N, Horimasu Y, Hattori N, Hirohashi N, Tanigawa K, et al. Baseline KL-6 predicts increased risk for acute exacerbation of idiopathic pulmonary fibrosis. Respir Med. 2014;108(7):1031-9.

5. Samukawa T, Hamada T, Uto H, Yanagi M, Tsukuya G, Nosaki T, et al. The elevation of serum napsin $A$ in idiopathic pulmonary fibrosis, compared with $\mathrm{KL}-6$, surfactant protein-A and surfactant protein-D. BMC Pulm Med. 2012;12:55

6. Ten Klooster L, van Moorsel CH, Kwakkel-van Erp JM, van Velzen-Blad H, Grutters JC. IgA in serum: An old acquaintance as a new prognostic biomarker in Idiopathic Pulmonary Fibrosis. Clin Exp Immunol. 2015;181(2):357-61.

7. Tajiri M, Okamoto M, Fujimoto K, Johkoh T, Ono J, Tominaga M, et al. Serum level of periostin can predict long-term outcome of idiopathic pulmonary fibrosis. Respir Investig. 2015;53(2):73-81.

8. Ley B, Brown KK, Collard HR. Molecular biomarkers in idiopathic pulmonary fibrosis. Am J Physiol Lung Cell Mol Physiol. 2014;307(9):L681-91.

9. Zhang $Y$, Kaminski N. Biomarkers in idiopathic pulmonary fibrosis. Curr Opin Pulm Med. 2012;18(5):441-6.

10. Hirota N, Ito T, Miyazaki S, Ebina M, Homma S. Gene expression profiling of lung myofibroblasts reveals the anti-fibrotic effects of cyclosporine. Tohoku J Exp Med. 2014;233(4):283-93.

11. Ruan W, Ying K. Abnormal expression of IGF-binding proteins, an initiating event in idiopathic pulmonary fibrosis? Pathol Res Pract. 2010;206(8):537-43.

12. Chadelat K, Boule M, Corroyer S, Fauroux B, Delaisi B, Tournier G, et al. Expression of insulin-like growth factors and their binding proteins by bronchoalveolar cells from children with and without interstitial lung disease. Eur Respir J. 1998;11(6):1329-36.

13. Mouhieddine OB, Cazals V, Maitre B, Le Bouc Y, Chadelat K, Clement A. Insulin-like growth factor-II (IGF-II), type 2 IGF receptor, and IGF-binding protein-2 gene expression in rat lung alveolar epithelial cells: relation to proliferation. Endocrinology. 1994;135(1):83-91.

14. Cazals V, Mouhieddine B, Maitre B, Le Bouc Y, Chadelat K, Brody JS, et al. Insulin-like growth factors, their binding proteins, and transforming growth factor-beta 1 in oxidant-arrested lung alveolar epithelial cells. J Biol Chem. 1994;269(19):14111-7.

15. Mouhieddine OB, Cazals V, Kuto E, Le Bouc Y, Clement A. Glucocorticoidinduced growth arrest of lung alveolar epithelial cells is associated with increased production of insulin-like growth factor binding protein-2. Endocrinology. 1996;137(1):287-95. 
16. Duan C. Specifying the cellular responses to IGF signals: roles of IGF-binding proteins. J Endocrinol. 2002;175(1):41-54.

17. Perks CM, Newcomb PV, Norman MR, Holly JM. Effect of insulin-like growth factor binding protein-1 on integrin signalling and the induction of apoptosis in human breast cancer cells. J Mol Endocrinol. 1999;22(2):141-50.

18. Jones Jl, Gockerman A, Busby Jr WH, Wright G, Clemmons DR. Insulin-like growth factor binding protein 1 stimulates cell migration and binds to the alpha 5 beta 1 integrin by means of its Arg-Gly-Asp sequence. Proc Natl Acad Sci U S A. 1993;90(22):10553-7.

19. Firth SM, Baxter RC. Cellular actions of the insulin-like growth factor binding proteins. Endocr Rev. 2002;23(6):824-54.

20. Duan $C, X u$ Q. Roles of insulin-like growth factor (IGF) binding proteins in regulating IGF actions. Gen Comp Endocrinol. 2005;142(1-2):44-52.

21. Yau SW, Azar WJ, Sabin MA, Werther GA, Russo VC. IGFBP-2 - taking the lead in growth, metabolism and cancer. J Cell Commun Signal. 2015;9(2):125-42.

22. Baxter RC, Binoux M, Clemmons DR, Conover C, Drop SL, Holly JM, et al. Recommendations for nomenclature of the insulin-like growth factor binding protein (IGFBP) superfamily. Growth Horm IGF Res. 1998;8(3):273-4.

23. Kim HS, Nagalla $S R$, Oh Y, Wilson E, Roberts Jr CT, Rosenfeld RG. Identification of a family of low-affinity insulin-like growth factor binding proteins (IGFBPs): characterization of connective tissue growth factor as a member of the IGFBP superfamily. Proc Natl Acad Sci U S A. 1997:94(24):12981-6.

24. Shimasaki S, Ling N. Identification and molecular characterization of insulin-like growth factor binding proteins (IGFBP-1, $-2,-3,-4,-5$ and -6$)$. Prog Growth Factor Res. 1991;3(4):243-66.

25. Pickard A, McCance DJ. IGF-Binding Protein 2 - Oncogene or Tumor Suppressor? Front Endocrinol. 2015;6:25.

26. Miller MR, Crapo R, Hankinson J, Brusasco V, Burgos F, Casaburi R, et al. General considerations for lung function testing. Eur Respir J. 2005;26(1):153-61.

27. Besnard V, Corroyer S, Trugnan G, Chadelat K, Nabeyrat E, Cazals V, et al. Distinct patterns of insulin-like growth factor binding protein (IGFBP)-2 and IGFBP-3 expression in oxidant exposed lung epithelial cells. Biochim Biophys Acta. 2001:1538(1):47-58

28. Miell JP, Taylor AM, Jones J, Holly JM, Gaillard RC, Pralong FP, et al. The effects of dexamethasone treatment on immunoreactive and bioactive insulin-like growth factors (IGFs) and IGF-binding proteins in normal male volunteers. J Endocrinol. 1993;136(3):525-33.

29. Furuhashi K, Suda T, Nakamura Y, Inui N, Hashimoto D, Miwa S, et al. Increased expression of YKL-40, a chitinase-like protein, in serum and lung of patients with idiopathic pulmonary fibrosis. Respir Med. 2010;104(8):1204-10.

30. Korthagen NM, van Moorsel CH, Barlo NP, Ruven HJ, Kruit A, Heron M, et al. Serum and BALF YKL-40 levels are predictors of survival in idiopathic pulmonary fibrosis. Respir Med. 2011;105(1):106-13.

31. Hung CF, Rohani MG, Lee SS, Chen P, Schnapp LM. Role of IGF-1 pathway in lung fibroblast activation. Respir Res. 2013;14:102.

32. Bagnato $\mathrm{G}$, Harari $\mathrm{S}$. Cellular interactions in the pathogenesis of interstitial lung diseases. Eur Respir Rev. 2015;24(135):102-14.

33. Russo VC, Azar WJ, Yau SW, Sabin MA, Werther GA. IGFBP-2: The dark horse in metabolism and cancer. Cytokine Growth Factor Rev. 2014;26(3):329-46.

34. Kelley KM, Oh Y, Gargosky SE, Gucev Z, Matsumoto T, Hwa V, et al. Insulinlike growth factor-binding proteins (IGFBPs) and their regulatory dynamics. Int J Biochem Cell Biol. 1996;28(6):619-37.

35. Jones Jl, Clemmons DR. Insulin-like growth factors and their binding proteins: biological actions. Endocr Rev. 1995;16(1):3-34.

36. Reeve JG, Morgan J, Schwander J, Bleehen NM. Role for membrane and secreted insulin-like growth factor-binding protein-2 in the regulation of insulin-like growth factor action in lung tumors. Cancer Res. 1993;53(19):4680-5.

37. Ahasic AM, Zhai R, Su L, Zhao Y, Aronis KN, Thompson BT, et al. IGF1 and IGFBP3 in acute respiratory distress syndrome. Eur J Endocrinol. 2012;166(1):121-9.

38. Alhamad EH, Cal JG, Shakoor Z, Almogren A, AlBoukai AA. Cytokine gene polymorphisms and serum cytokine levels in patients with idiopathic pulmonary fibrosis. BMC Med Genet. 2013;14:66.

39. Khalil N, Greenberg AH. The role of TGF-beta in pulmonary fibrosis. Ciba Found Symp. 1991;157:194-207. discussion -11.

\section{Submit your next manuscript to BioMed Central and we will help you at every step:}

- We accept pre-submission inquiries

- Our selector tool helps you to find the most relevant journal

- We provide round the clock customer support

- Convenient online submission

- Thorough peer review

- Inclusion in PubMed and all major indexing services

- Maximum visibility for your research

Submit your manuscript at www.biomedcentral.com/submit
Biomed Central 